\title{
Exploring Possible Seasonal Trends in Mortality Rate in Relation to Age, Gender and Environmental Conditions in Kuwait: A Preliminary Analysis
}

\author{
N. Al-Rifaia*, A. Elmi and A.R. Khan \\ College for Women, Department of Environmental Technology Management, University of Kuwait, P.O. Box 5969, \\ Safat 13060, Kuwait
}

Received 7 October 2009; accepted 6 January 2010

$$
\text { استكشاف احتمالية وجود علاقات فصلية في معدل الوفيات و علاقتها بالعمر و الجنس و الاحوال البيئية في الكويت: }
$$

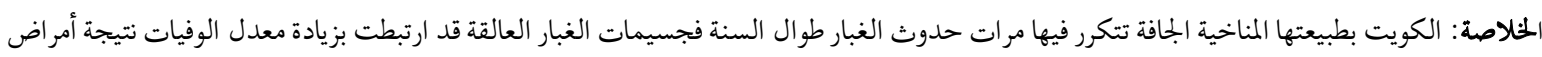

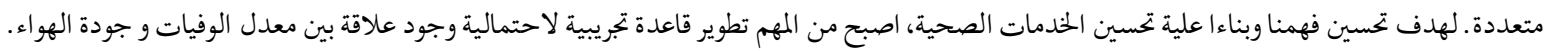

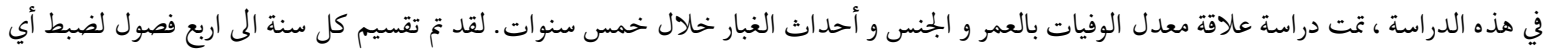

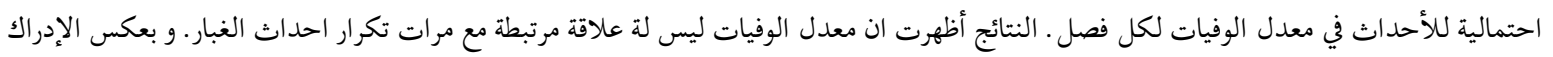

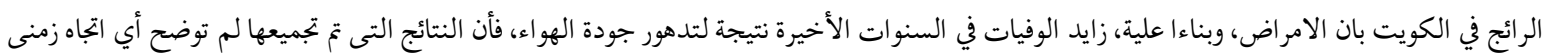

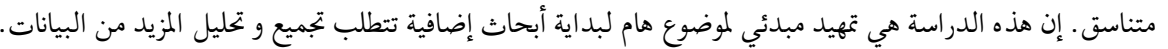

المفردات المفتاحية: جودة الهواء، أحداث الغبار، الوفيات، تلوث.

\begin{abstract}
Inherently, Kuwait a high frequency of dusty events through out the year due to its arid climate. Particulate air pollution has been linked to increased mortality due to various illnesses. For the purpose of improving health services, it is important to develop/establish an empirical basis for the possible link between mortality and air quality. In this paper, we examined mortality rates in Kuwait in relation to age, sex and dust episodes during a five-year period. Each year was divided into four seasons to detect any potential episodes in the death rate for a particular season. The results showed that the mortality rates did not correlate significantly $(p=0.67)$ with the occurrence of total dust events. Contrary to the popular perception in Kuwait that illnesses and, consequently, deaths increased in recent years as a result of deteriorating air quality due to particulate matter, the collected data did not show a consistent temporal trend. While this work represents an initial effort on an important issue upon which further investigations can be elaborated upon, a more detailed data have to be collected and analyzed.
\end{abstract}

Keywords: Air quality, Dust episodes, Mortality, Pollution

\section{Introduction}

A large number of environmentally related health studies has been conducted in different countries during the past several decades, which reveals that poor air quality contributes to increasing numbers of illnesses and deaths among adults and children (Brunekreef and Holgate, 2002). There has been growing public concern in Kuwait in recent years, like other countries in the world, about health problems associated with deteriorating air quality. This is atleast partly because, Kuwait has been exposed to various types of fine particles that may have originated from oil fires blamed for the ecological destruction caused by the Iraqi invasion. It may also be because of and other particulates due to dry/wet deposition such as sulfate, nitrate and POPs (Persistent Organic Pollutants), which are derived chiefly from the combustion of fossil fuels in oil production, transportation, refining and power generation plants. Fine particles are of the greatest health concern, especially when they are saturat-

\footnotetext{
*Corresponding author's e-mail: nahla@alaswar.net
} 
ed with hydrocarbons, because they can be inhaled deep into the lungs. Respiratory and cardiovascular mortality were found to be related to $\mathrm{PM}_{10}$ (Miller et al. 1979). Coarse particles that are transported long distance with high wind speeds are also a health risk (Ostro et al. 1999; Schwartz et al. 1999; Kwon et al. 2002). Adverse effects of air pollution include an increase in cardiovascular and respiratory diseases leading to a high rate of deaths among elderly people (Delucchi et al. 2002 and Morris, 2001). A brief review of these studies is provided by Chen et al. (2004).

Although there is strong evidence that particulate matter adversely affects human health, the precise proportion of mortality attributable to deteriorated air quality is difficult to quantify, due to complex interactions among many factors. For example, Chen et al. (2004) studied the effect of Asian dust storm events during spring on daily mortality in Taipei, Taiwan, during the period 1995-2000. They found no statistically significant relationship between dust storms and mortality rate. Several other studies have also addressed the relationship between particulate air pollution and daily mortality at low levels of exposure (Schwartz and Marcus, 1990). Schwartz (1991) analyzed the relationship between air pollution and daily mortality in Detroit, for 1973 to 1982. Mortality in Philadelphia due to TSP and $\mathrm{SO}_{2}$ was studied over the years 1973 to 1980 (Schwartz and Dockery, 1992). These workers reanalyzed mortality data from London for the winters of 1958 to 1972 and they found no evidence of a threshold in the relationship between black smoke and total daily mortality. Therefore, it remains unclear the lowest level of black smoke above which significant relationships between air pollution and daily mortality could be found.

To our knowledge, no specific published study has yet explored the link between deteriorating air quality and health problems in Kuwait. Furthermore, air pollution levels differ dramatically with respect to seasons. Consequently, the estimated effect of air pollution on daily mortality might be different in different seasons. The primary objective of this study is to explore possible relationship between the four seasons and the mortality rates of different age groups during the period 1999-2005 in Kuwait. Although mortality rate studies data show the largest effects among elderly people (Dominci et al. 2003 ), in the current study, all ages have been included to build up a general view of a preliminary investigation into whether there are any specific season(s) in which there is an increases in overall mortality in Kuwait for both males and females.

\section{Data Collection and Analysis}

The data were collected from the publications of the department of Statistics and Medical records of the Kuwait Ministry of Health, from1998-to-2005, as well as from the annual reports of population statistics issues (1998-2005) from the Kuwait Ministry of Planning.
Particulate air pollution data were obtained from environmental public authority (EPA) station located at the Polyclinic in Ali Sabah Al-Salem residential area, about $47 \mathrm{~km}$ south Kuwait city. The data collected were presented as total number of death per month for eight age group sectors for Kuwaiti Male and Female. Metrological data were obtained from Kuwait International Airport for the entire period of concern.

Each year was divided into four seasons: winter (the three adjoining months of December, January, and February), spring (March, April, and May), summer (June, July, and August) and fall (September, October, and November). The seasonal monthly average was calculated and divided by the total Kuwaiti population of males or females for each specific year to normalize the data. These normalized data are presented as number of deaths per million people.

Analysis of variance (ANOVA) was performed separately on each season within a year. Data were analyzed statistically as a factorial design with three main factors: age of 8 groups $(<1-9,10-19,20-29,30-39,40-49,50-59$, 60-69, and 70->70), sex (male and female) and seasons (winter, spring, summer, and fall). When interactions of the main factors were significant, interactions rather than individual factors are discussed. Similarly, when a main factor's effect was significant without any interaction, Fisher's F test statistic was used to determine statistical significance within each main factor at a probability level of $0.05(\alpha=0.05)$. Once the data has been tested, preplanned LSD (Least Significant Difference) multiple comparisons were used on the factors which were found to be significant to quantify the differences. All statistical analyses were conducted using the Statistical Analysis System, SAS (2004) for Windows.

\section{Results and Discussion}

A summary of the statistical analysis of the results of the main and interaction effects is presented in Table 1. The results show that the effects of all the main factors' significant except for seasons in 2002 and 2003. We found that interaction between age and gender are significant $(p<0.05)$ for all the years investigated except 2005, with 2001 being statistically on the border $(p=0.06)$. Also, another striking aspect of these findings is that genderand-season interaction was not significant in any year except 2004 (Table 1). This is an indication that male and female mortality rates behaved similarly in relation to season. The result also shows that age-and-season interaction was significant for only 2000. This is consistent with the observations that elderly people are affected the most, especially during spring and winter seasons as discussed in detail in the following section.

Figures 1 to 4 present normalized death rates in Kuwait for female and males from 1999 to 2005 . The normalization was based on dividing the number of deaths for a particular age group in each year by the total population of 
Table 1. Summary of the analysis of variance ( $P$-value) statistical from $1999-2003$ using GLM procedure

\begin{tabular}{|l|c|c|c|c|c|c|c|}
\hline & $\mathbf{1 9 9 9}$ & $\mathbf{2 0 0 0}$ & $\mathbf{2 0 0 1}$ & $\mathbf{2 0 0 2}$ & $\mathbf{2 0 0 3}$ & $\mathbf{2 0 0 4}$ & $\mathbf{2 0 0 5}$ \\
\hline Age & 0.0001 & 0.0001 & 0.0001 & 0.0001 & 0.0001 & 0.0001 & 0.0001 \\
\hline Sex & 0.0001 & 0.0001 & 0.0001 & 0.0001 & 0.0001 & 0.0001 & 0.0001 \\
\hline Season & $\mathbf{0 . 0 0 5 4}$ & $\mathbf{0 . 0 0 0 1}$ & $\mathbf{0 . 0 2 3 6}$ & 0.2624 & $\underline{0.0763}$ & $\mathbf{0 . 0 0 0 2}$ & $\mathbf{0 . 0 0 3 6}$ \\
\hline Age*Sex & $\mathbf{0 . 0 1 3 2}$ & $\mathbf{0 . 0 3 2 0}$ & 0.0604 & $\mathbf{0 . 0 0 0 4}$ & $\mathbf{0 . 0 1 5 5}$ & $\mathbf{0 . 0 0 4 5}$ & 0.2534 \\
\hline Age*Season & 0.2511 & $\mathbf{0 . 0 0 0 9}$ & 0.1132 & $\underline{0.0878}$ & 0.8822 & 0.1175 & $\underline{0.0733}$ \\
\hline Sex*Season & 0.6107 & 0.9811 & 0.9930 & 0.3102 & 0.6731 & $\mathbf{0 . 0 1 9 4}$ & 0.3558 \\
\hline
\end{tabular}
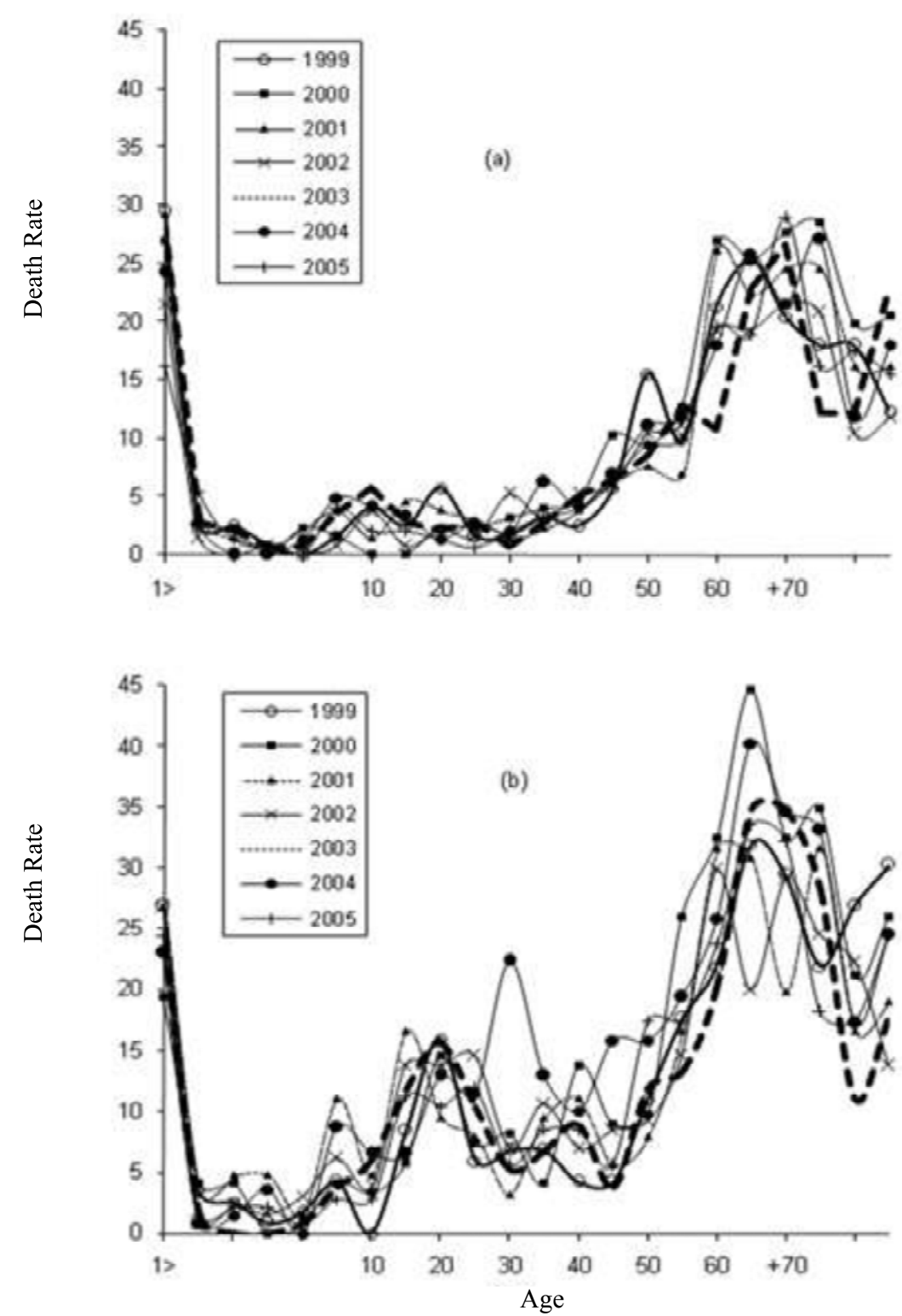

Figure 1. Death rates in Kuwait for (a) female and (b) males during winter season from 1999 to 2005 

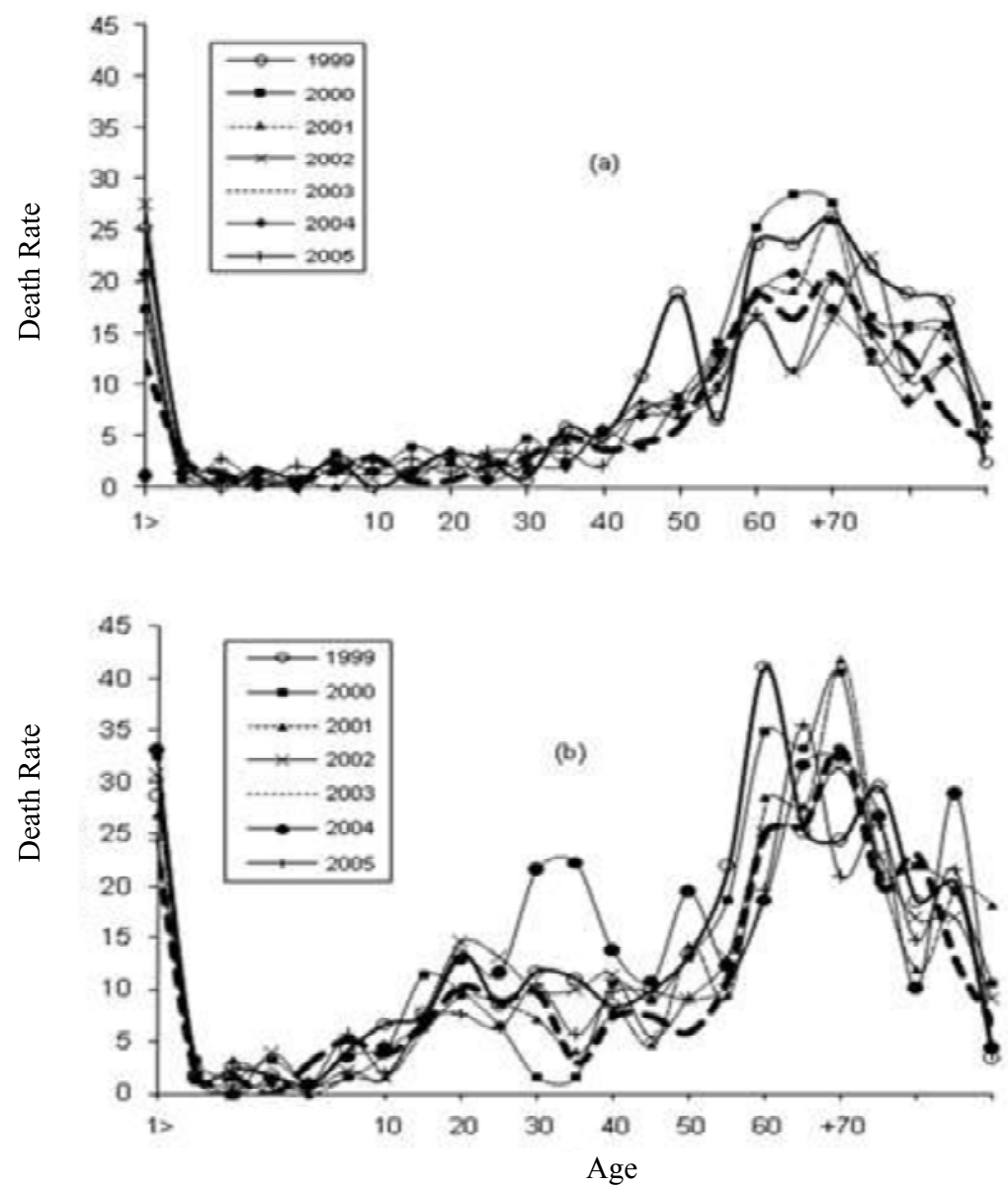

Figure 2. Death rates in Kuwait for (a) female and (b) males during spring season from 1999 to 2005
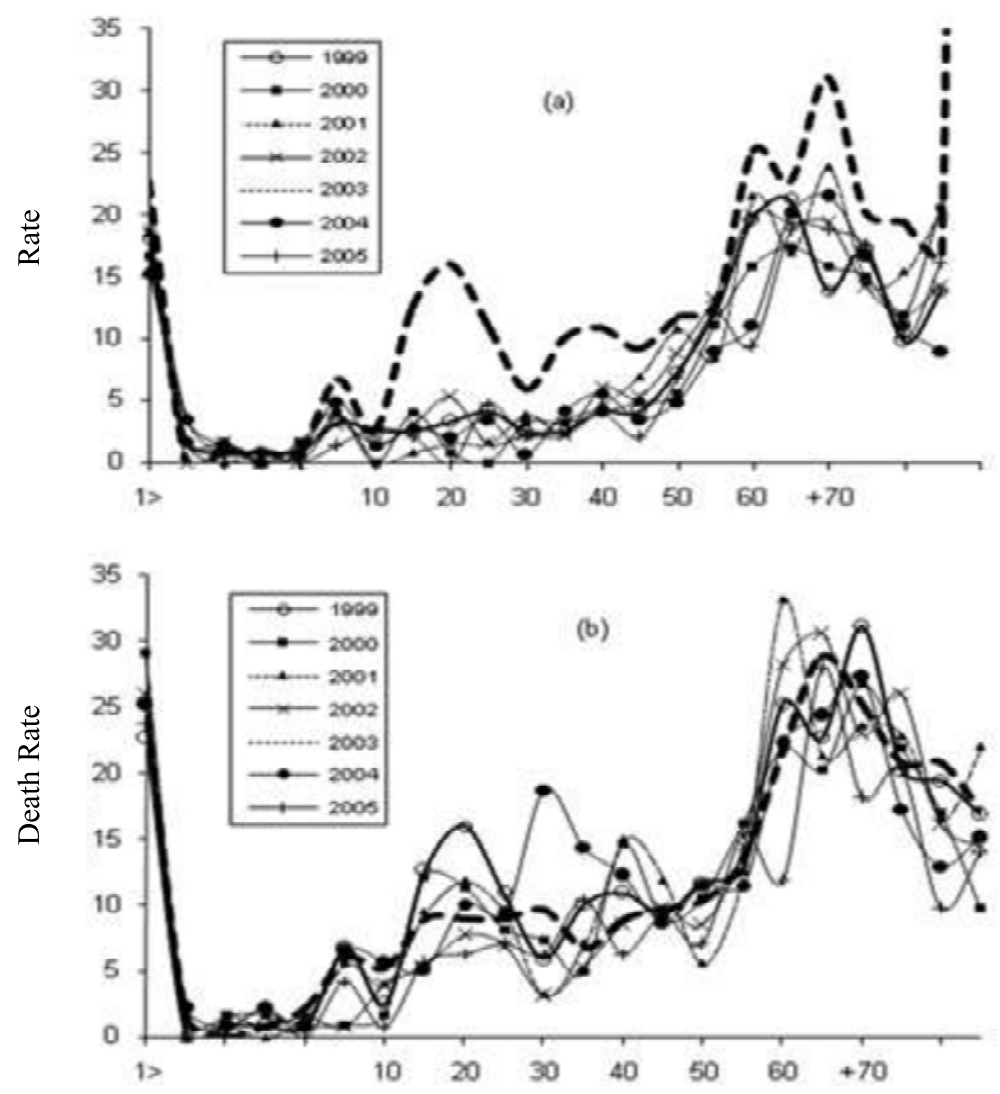

Figure 3. Death rates in Kuwait for (a) female and (b) males during fall season season from 1999 to 2005 

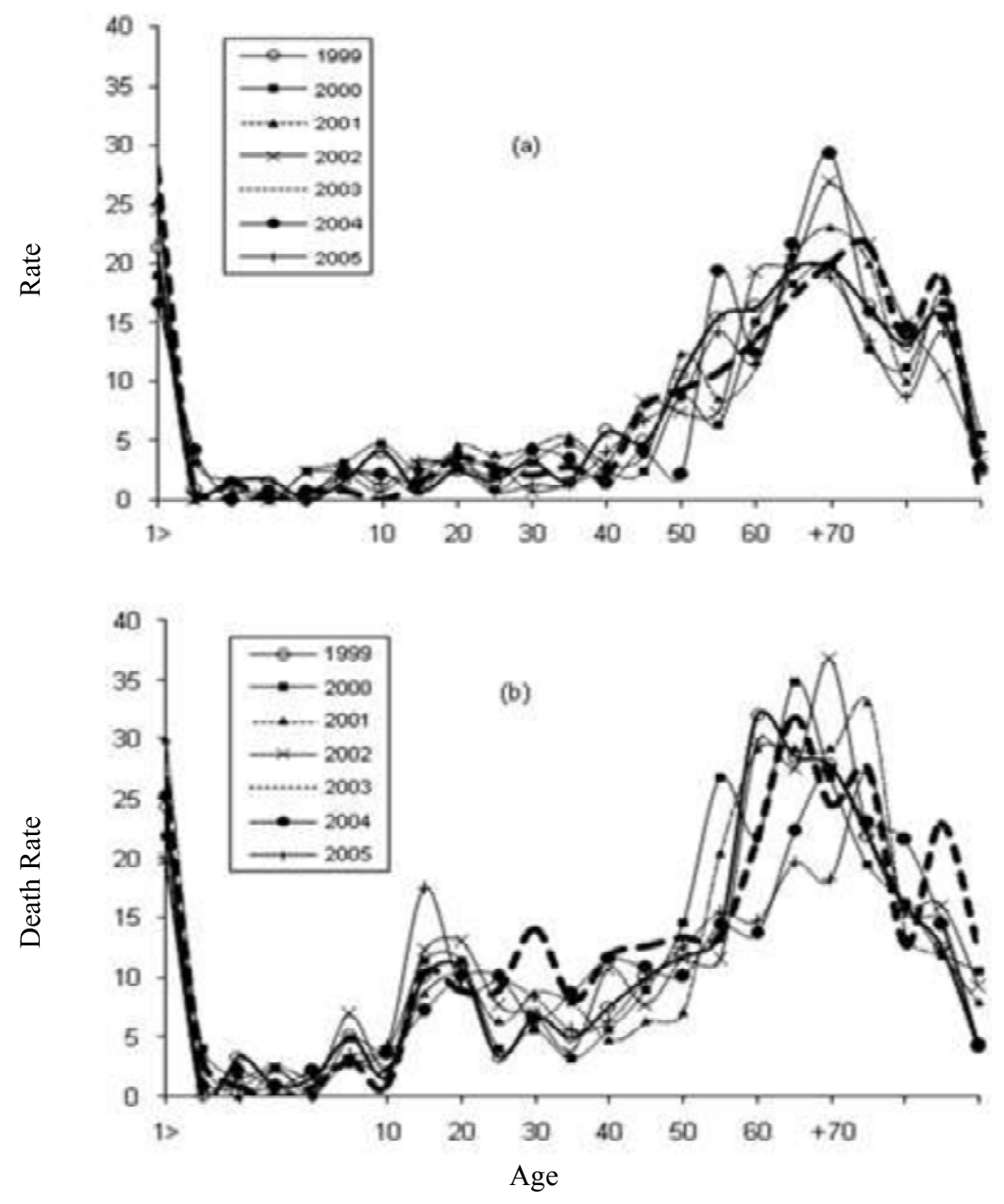

Figure 4. Death rates in Kuwait for (a) female and (b) males during summer season from 1999 to 2005

that year. (For back calculation, we multiplied by a million). The effect of the growing population on the number of deaths has thus been eliminated. In general, it was observed that there was a higher death rate for males of age of 15-35 in all seasons than for females, the fall season of 2003, when the female death rate matched that of males. One of the most plausible explanations is the high number of deadly traffic accidents among the teenage male population. However, to verify this hypothesis, there is a need for further investigation. It was also obvious from our data that the death rate dropped for the older age group (beyond 70) for both male and female due to dwindling numbers of both sexes as expected. It appears that most people die at the age group 65-70 and a few died in the older age group as explained later. This study included all reasons of death, which were in some years high for fatal diseases, accidents, circulatory system, cancer, respiratory and heart diseases over other years.

The number of deaths for the age group of 20-25 years was found to be higher than the average for males in the winter of 1999, 2002 and 2004 (Figure 1b) in the spring of 2000, 2002 and 2004 (Figure 2b), in the summer of 1999 and 2000 (Figure 3b) and in the fall of 2002 (Figure 4b). However, the death rate for the age group of 30-35 was higher than the mean only for males in the winter and summer of 2004 and fall of 2003 (Figure 4b), and for females in the summer of 2003 (Figure 3a). Mortality occurred mostly among the elderly; it was noticed that total number of deaths for both males and females increased with age, the maximum being in the range of 60-70 years. This trend is true for all the seasons in each year, which is consistent with the literature (eg. Delucchi et al. 2002). This may have been due to the generally poorer health condition of elderly people, which was exacerbated by deteriorating air quality. Average deaths for this particular age group was higher for spring and winter of 2000 and then it declined in the following years. This decline in the mortality rate may be due to improved health care services, since we did not observe any noticeable decrease in air pollutants. However, the somewhat good news (decline in the mortality rate) did not last long as there was an increasing trend for total death towards 2002-2003 in most of the seasons, especially in winter. The pollution levels in winter are always high due to lower temperatures, high humidity and the low planetary boundary layer resulting in a build-up due to inadequate dispersion (Khan and Al-Salem, 2007).

Based on the age groups the highest seasonal death rate 
Table 2. Total number of Haze, suspended dust, raising dust and dust storms days in Kuwait for the period 1999 - 2005 per season

\begin{tabular}{|l|c|c|c|c|c|}
\hline & Winter & Spring & Summer & Fall & Total \\
\hline $\mathbf{1 9 9 9}$ & 49 & 65 & 126 & 74 & 314 \\
\hline $\mathbf{2 0 0 0}$ & 67 & 131 & 168 & 82 & 448 \\
\hline $\mathbf{2 0 0 1}$ & 76 & 106 & 114 & 79 & 375 \\
\hline $\mathbf{2 0 0 2}$ & 98 & 98 & 144 & 98 & 438 \\
\hline $\mathbf{2 0 0 3}$ & 111 & 144 & 174 & 113 & 542 \\
\hline $\mathbf{2 0 0 4}$ & 85 & 103 & 127 & 109 & 424 \\
\hline $\mathbf{2 0 0 5}$ & 74 & 107 & 155 & 80 & 416 \\
\hline
\end{tabular}

Table 3. Annual total number of unstated age of death as compared to total number of deaths

\begin{tabular}{|l|l|l|l|l|l|l|}
\hline \multirow{2}{*}{ Year } & \multicolumn{4}{|c|}{ Unstated } & \multicolumn{3}{c|}{ Total } \\
\cline { 2 - 7 } & M & F & M+F & M & F & M+F \\
\hline 1999 & 25 & 17 & 42 & 1384 & 966 & 2350 \\
\hline 2000 & 66 & 41 & 107 & 1448 & 972 & 2420 \\
\hline 2001 & 61 & 33 & 94 & 1440 & 1005 & 2445 \\
\hline 2002 & 37 & 22 & 59 & 1423 & 988 & 2411 \\
\hline 2003 & 38 & 23 & 61 & 1490 & 962 & 2452 \\
\hline 2004 & 29 & 15 & 44 & 1652 & 1021 & 2673 \\
\hline 2005 & 28 & 23 & 51 & 1288 & 901 & 2189 \\
\hline
\end{tabular}

for males, is 44.62 in year 2000 for age group $70>$ age $>60$ while the second highest was 40.28 in year 2004 for the age group $70>$ age $>60$. For females the highest seasonal death rate was 29.44 in the year 1999 for the age group $<1$ year while the second highest is 29.23 in year 2001 for the age group $<1$ year, (fig. 1).

In spring the average seasonal death rate for all ages was 260.9 for males (about $61.7 \%$ of the total reported deaths) and 161.7 for females (38.6\%) Based on age groups, the highest seasonal death rate for males, was 41.87 in year 2001 for the $75>$ age $>65$ age group while the second highest was 41.21 in year 1999 for the $65>$ age $>55$ age group. For females the highest seasonal death rate was 28.52 in year 2000 for the $70>$ age $>60$ age group while the second highest was 27.49 in year 2002 for the $<1$ year age group, (fig. 2).

The average seasonal death rate for all ages was at a minimum in summer for both sexes: 250.8 males (about $60.7 \%$ of the total reported deaths) and 162.2 females $(39.3 \%)$. For males, the highest seasonal death rate was 33.18 in year 2001 for the $65>$ age $>55$ age group while the second highest was 31.12 in year 1999 for the $75>$ age $>65$ age group. For females the highest seasonal death rate was 31.11 in year 2003 for the $75>$ age $>65$ age group while the second highest was 23.84 in year 2001 for the $75>$ age $>65$ age group, (fig. 3). In summer the frequency of dust storms is high. Strong winds and high temperatures facilitate dispersion of pollutants. The demand for electrical power raises the power load to peak, forcing the power stations to operate in full capacity and thus emitting more pollutants.

In fall the average seasonal death rate for all ages was 242.5 for males (about $61.3 \%$ of the total reported deaths) and $154.2(38.9 \%)$ for females. For males, the highest seasonal death rate was 36.71 in year 2002 for the $75>$ age $>65$ age group while the second highest was 34.89 in year 2000 for the $70>$ age $>60$ age group. For females the highest seasonal death rate was 29.20 in year 2004 for the $75>$ age $>65$ age group while the second highest was 28.01 in 2003 for the $<1 y$ age group, (fig. 4).

Overall, from the analysis of 5 years of data, it was noted that the average seasonal death rate for all ages was maximum in winter for both sexes: 297.6 males, (about $59.5 \%$ ) and 202.9 females (about $40.5 \%$ ) of the total reported deaths.

The effects of poor air quality on daily mortality could be delayed for an unexpected period, depending on the initial health condition of individuals. Since the number of days in which there were measurable dusty events (rising dust, suspended dust, dust storms, and haze) increased 
The Journal of Engineering Research (2010) Vol. 8 No. 1 (2011) 19-27

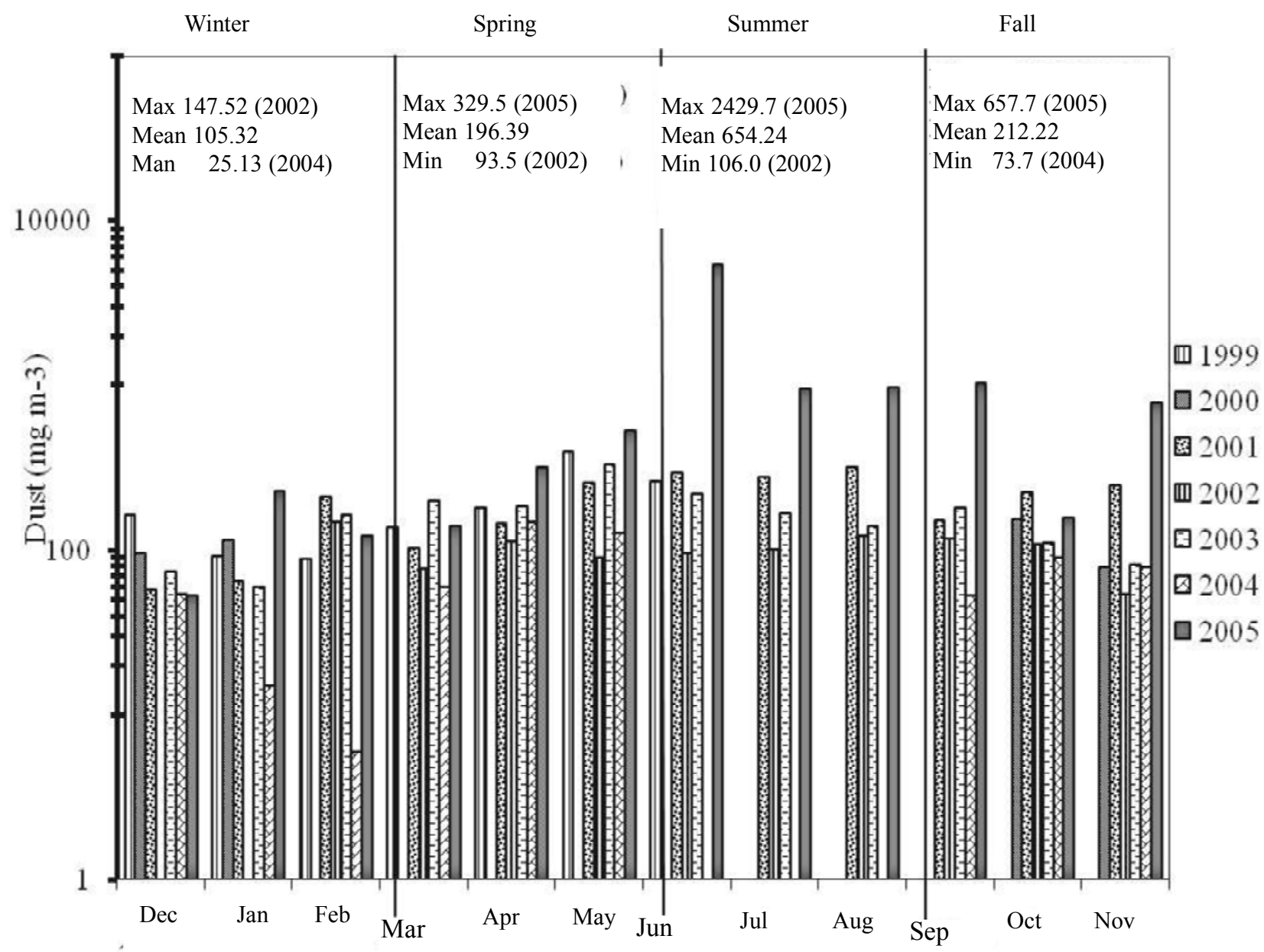

Months

Figure 5. Monthly dust measurement at Um-Alheaman Station

gradually over time with 2003 having the highest (Table 2 ), it was plausible to expect the death rate to continue to rise in subsequent years. Figure 5 shows the frequency of dusty events as a function of season variation for the seven-year period 1999 to 2005 . A maximum concentration of particulate matter was observed in the summer season of year 2005 and minimum concentration was in winter season of year 2004. In the summer season, the dust storms are more frequent as compared to any other season while in winter the frequency of dusty events is minimum, based on the data of these 7 years.

By comparing Table 2 with figs. 1 to 4 , one would observe that the total number of days with haze, suspended dust, rising dust and dust storms was highest in summer and the lowest in winter, while the mortality rate was highest in winter and lowest in summer. This could be because the victims, especially the elderly died after a period of illness. In Kuwait, pollutants concentrations, as reported by Khan and Salem (2007), and Al-Azmi et al. (2008), are generally higher in the winter season as com- pared to summer due to prevalent meteorological conditions such as low temperatures, slow winds and a lower planetary boundary layer (PBL) in winter. Middleton et al. 2008 observed an increased risk of hospitalization at elevated levels of particulate matter and ozone on dusty storm days. Similarly, Perez et al. (2008) found convincing associations of mortality with course Saharan dust (but not with local coarse dust). Such hypothesis which relates the effect of dusty seasons or air quality to specific causes of death may require daily monitoring of hospital admissions and patient history. However, this is beyond the scope of this research and requires further investigation. The time series models require daily death rate data, which are not available.

The death rate $p>0.67$ did not correlate significantly with the pooled environmental air quality data for all types of dusts for either females or males or for the total, in any of the investigated seasons. The lack of any significant association between particulate type of pollutants reported herein and mortality rates limited our ability to address the 
precise effects of particulate air pollution on daily mortality, in relation to gender, season, and age. Complex interactions among these factors might have masked any significant individual effects. The computation of correlation coefficients among age, season, gender, and air quality was complicated by the fact that there was a large number of deaths with unstated age at the time of death over all the years (Table 3), indicating that full demographic information, such as date of death, were not recorded accurately. Therefore, data on the age at the time of death are excluded from the analysis. More accurate recordkeeping of data such as date of patient sickness before death, reason of death, place of death etc. so that more detailed data analysis can be done.

Several studies conducted in the USA suggest that current levels of particulate pollution in urban air are associated not only with short-term but also with long-term increases in respiratory morbidity, mortality as well as lung cancer. For example, Nevalainen and Pekkanen (1998) evaluated the change in life expectancy assuming the long-term increase in mortality. They found the effect of particulate air pollution on life expectancy to be notable in countries with high cardiovascular mortality like USA. Barceló et al. (2009) have reported deprivation to be associated in a statistically significant way with the geographical variation in mortality in the census tracts of the metropolitan area of Barcelona, in the period 1994 to 2003. In our study however, there were no significant $(p>0.05)$ temporal trends of increased/decreased death rates for either females or males for all the seasons investigated during five consecutive years (figs. 1-4), except in the 6570 age group. It should be noted however, that all death data presented in this paper are reported both inside and outside hospitals. Schwartz, 2001 reported that airborne particles had greater impacts on deaths outside the hospital in Chicago, suggesting that exposure to particles increases the risk of sudden deaths. Vaneckova et al. (2009) reported that $\mathrm{O}_{3}$ and $\mathrm{PM}_{10}$ were found to be nonsignificant factors in the regions where air pollutants were studied. Socio-economic status and the proportion of vegetation or developed land in each Statistical Local Area (SLA) were also not a significant factor explaining the increased mortality. Trigo el al. 2009 have presented the impact of the European heat wave in 2003 on mortality in Portugal. The mortality of women increased $79 \%$ while men had a $41 \%$ increases in all 18 districts of the country.

Prediction of death rates for various seasons is quite difficult because death can occur for any reason, particularly through unexpected accidents, a leading cause of death among the youth. It should be noted however, that the poor correlation between dusty days and mortality rates does not mean that air quality has no effect on mortality. The effect of other pollutants and the combination of particulate matter with other pollutants on all types of death due to respiratory illnesses will be the focus of our next research.

\section{Conclusions}

The significance of air pollution in terms of public health has been recognized worldwide, and Kuwait is no exception. The primary aim of this paper was to analyze available data to see whether or not there is an increasing trend in mortality in relation to season, gender and age sector. We found that this type of mortality occurred mostly among the elderly. A correlation analysis showed no significant $(p>0.05)$ association between death rates and air quality indicators. Given the inherent limitations of risk assessments, further studies are needed to support and quantify the relationship between mortality rate and air pollution under Kuwait living conditions so that appropriate public health policies can be developed. We plan to carry out a more in-depth investigation of deaths that are directly related to pollution, such as specific death cases as a result of respiratory and lung cancer.

\section{Acknowledgment}

We thank the Department of Statistics and Medical Records at Kuwait Ministry of Health, and Statistics and Census Sector at Kuwait Ministry of Planning for providing us with the data. We also thank Mr. Kasem El-Fadli of the Directorate General of Civil Aviation, the Meteorological Department, the Climatologically Division and the Environmental Public Authority (EPA) for providing us with dust measurement data. Finally, we are thankful to Miss Muneera Al-Qassar for her assistance in the data management.

\section{Reference}

Al-Azmi, B. N., Nassehi V. and Khan, A. R., 2008, "Comparative Assessment of Ambient Air Quality in Rabia for year 2001 and 2004 in the State of Kuwait," American Journal Environmental Sciences, Vol. 4 (1), pp. 50-62.

Barceló, M. A., Saez, M. and Saurina, C., 2009, "Spatial Variability in Mortality Inequalities, Socioeconomic Deprivation, and Air Pollution in Small Areas of the Barcelona Metropolitan Region, Spain," Science of the Total Environment, Vol. 407, pp. 5501-5523.

Brunekreef, B. and Holgate, S.T., 2002, "Air Pollution and Health," Lancet Vol. 360, pp. 1233-1242.

Chen, Y.S., Sheen, P.C., Chen, E.R., Liu, Y.K., Wu, T.N. and Yang, C.Y., 2004, "Effects of Asian Dust Storm Events on Daily Mortality in Taipei, Taiwan," Environmental Research, Vol. 95, pp. 151-155.

Delucchi, M.A., Murphy, J.J. and McCubbin, D.R., 2002, "The Health and Visibility Cost of Air Pollution: A Comparison of Estimation Methods," Journal of Environmental Management, Vol. 64, pp. 139-152

Dominci, F., Aidan, M.C., Zeger, S. and Same, J., 2003, "Airborne Particulate Matter and Mortality: Time 
Effects in four US Cities," American Journal of Epidemiology, Vol. 157, pp. 1055-065.

Khan, A. and Al-Salem, S., 2007 "Seasonal Variation Effect on Airborne Pollutants in an Urban Area of the State of Kuwait," Journal of Environmental Research and Development, Vol. 1(3), pp. 215-218.

Kozlov, M.V., 2004, "Retrospective Analysis of the Age at Death in Two Heavily Polluted and Unpolluted Russian Towns," Chemosphere Vol. 56, pp. 405-410.

Kwon, H.J., Cho, S.H., Chun, Y., Lagarde, F. and Pershagen, G., 2002, "Effects of the Asian Dist Events on Daily Mortality in Seoul, Korea," Environmental Research, Vol. 90, pp. 1-5.

Middleton N., Yiallouros P., Kleanthous S., Kolokotroni O., Schwartz J., Dockery D.W., Demokritou P. and Koutrakis P., 2008, "A 10-year Time Series Analysis of Respiratory and Cardiovascular Morbidity in Nicosia, Cyprus: the Effect of Short-term Changes in Air Pollution and Dust Storms," Environmental Health, Vol. 7 (39), pp. 1-16.

Miller, F.J., Gardner, D.E., Graham, J.A., Lee, R.E. and Bachmann, J.D., 1979, "Size Considerations for Establishing a Standard for Exhalable Particles," Journal of Air Pollution Control Association, Vol. 29, pp. 610-615.

Morris, R.D., 2001, "Airborne Particulates and Hospital Admissions for Cardiovascular Disease: A Quantitative Review of the Evidence," Environmental Health Perspectives, Vol. 109, pp. 495-500.

Nevalainen J. and Pekkanen, J., 1998, "The Effect of Particulate Air Pollution on Life Expectancy," The Science of the Total Environment, Vol. 217, pp. 137141.

Ostro, B.D., Hurley, S. and Lipsett, M.J., 1999, "Air Pollution and Daily Mortality in the Coachella Valley, California: A Study of PM10 Dominated by Coarse Particles," Environmental Research, Vol. 81, pp. 231238.

Perez L., Tobias, A., Querol X., Kunzli N., Pey J., Alastuey A., Viana M., Valero N., Gonzalez-Cabre M. and Sunyer J., 2008, "Coarse Particles from Saharan Dust and Daily Mortality," Epidemiology, Vol. 19(6), pp. 800-807.

Pope, C.A, Schwartz, J. and Ransom, M.R., 1992, "Daily Mortality and PM10 Pollution in Utah Valley," Archives in Environmental Health, Vol. 47, pp. 211217.

SAS Institute Inc., 2004. Statistical Analysis System (SAS) Software Version 9.1.2, Cary, NC: SAS Institute Inc.

Schwartz, J. and Marcus, A., 1990, "Mortality and Air Pollution in London: a Time Series Analysis," American Journal of Epidemiology, Vol. 131, pp. 185-194.

Schwartz, J., 1991, "Particulate Air Pollution and Daily Mortality in Detroit," Environmental Research, Vol. 56, pp. 204-213.

Schwartz, J., 2001, "Is there Harvesting in the Association of Airborne Particles with Daily Deaths and Hospital Admissions," Epidemiology, Vol. 12, pp. 55-61.

Schwartz, J. and Dockery, D.W., 1992, "Increased Mortality in Philadelphia Associated with Daily Air Pollution Concentrations," American Review on Respiratory Diseases, Vol. 4, pp. 600-604.

Schwartz, J., Norris, G., Larson, T., Sheppard, L., Claiborne, C. and Koenig, J., 1999, "Episodes of High Coarse Particle Concentrations are not Associated with Increased Mortality," Environmental Health Perspectives, Vol. 107, pp. 339-342.

Trigo, R. M., Ramos, A. M., Nagueira, P. J., Santos, F. D., Garcia-Herrera, R., Gouveina, C. and Santo, F., 2009, "Evaluation of Impact of Extreme Temperature Based Indices in the 2003 Heat Wave Excessive Mortality in Portugal," Environmental. Environmental Science and Policy, Vol. 12, pp. 844854.

Vaneckova, P., Beggs, P. J. and Jacobson, C. R., 2010, "Spatial Analysis of Heat-Related Mortality among the Elderly between 1993 and 2004 in Sidney, Australia," Social Science and Medicine, (In press). 